\title{
Análise do Desempenho Econômico-Financeiro de Empresas Brasileiras que Realizaram Operações de Fusões e de Aquisições
}

\author{
Analysis of Economic and Financial Performance of Brazilian \\ Companies after Mergers and Acquisitions Operations
}

Emanoel Truta do Bomfim

Doutorando em Ciências Contábeis pela Universidade Federal da Paraíba - UFPB. Professor da Faculdade de Campina Grande FACCG. Campina Grande, PB. Brasil.E-mail: emanoeltruta@hotmail.com

\section{Aldo Leonardo Cunha Callado}

Doutor em Agronegócios. Professor Adjunto do Departamento de Finanças e Contabilidade da Universidade Federal da Paraíba. João Pessoa - PB. Brasil.E-mail: aldocallado@yahoo.com.br

\section{Resumo}

O objetivo principal desta pesquisa é identificar os efeitos provocados pelas fusões e aquisições no desempenho econômico-financeiro de empresas brasileiras de capital aberto que realizaram essas operações entre 2008 e 2012. Para testar a relação entre o desempenho econômico-financeiro das companhias após as fusões e as aquisições (F\&As), utilizou-se a técnica de dados em painel na forma dinâmica, sendo os modelos estimados pelo Método dos Momentos Generalizados-Sistema. As evidências indicam que o desempenho das companhias foi persistente após as operações, produzindo ganhos de desempenho e aumento no poder de mercado, pelas sinergias geradas e pelo aumento no tamanho das companhias; além disso, ainda, o crescimento interno produziu maior retorno se comparado ao crescimento por F\&A; e as operações financiadas por mais de uma modalidade de recursos reduziram o desempenho das empresas no período analisado. Portanto, observa-se que as F\&As são estratégias que podem gerar aumento na lucratividade das empresas após sua realização.

Palavras-chave: Fusões e Aquisições. Empresas Brasileiras. Desempenho Econômico-financeiro. Crescimento Interno. Sinergia.

\section{Abstract}

The objective of this paper is to identify the effects caused by mergers and acquisitions in the financial performance of Brazilian public companies that completed these operations between 2008 and 2012. To test the relationship between the financial performance of companies after the merger and acquisitions (M\&As), used the panel data technique dynamically, and the models estimated by the Generalized method of Moments-System. The findings reveal that the performance of companies was persistent after operations; produced performance gains; increase in market power, the synergies generated by the increase in the size of companies; the organic growth produced a higher return compared to the growth in $\mathrm{MrA}$; and that the operations financed by more than one resource modality reduced the performance of companies in the analyzed period. Thus, it is observed that $M \& A s$ are strategies that can generate increased corporate profitability after its realization.

Keywords: Mergers and Acquisitions. Brazilian Companies. Economic and Financial Performance. Internal Growth. Synergy. 


\section{INTRODUÇÃO}

As operações de fusões e aquisições (F\&As) são atividades corporativas dinâmicas que ainda geram muitos questionamentos quanto aos efeitos provocados sobre o desempenho organizacional das companhias adquirentes ou resultantes dessas combinações de negócios. De acordo com a KPMG (2013), no Brasil, entre os anos de 2008 e 2012, ocorreram mais de 3.400 operações de F\&As, sendo que mais de $35 \%$ dessas transações foram realizadas envolvendo apenas empresas nacionais.

Segundo a literatura, os processos de fusões $e$ aquisições são motivados por diferentes expectativas, como: obtenção de maior participação no mercado, obtenção de ganhos operacionais e financeiros, ganhos tributários, substituição de gestores, redução de custos de escala, meio estratégico para otimizar o uso dos ativos e de outros recursos, potencializar o crescimento das firmas, gerarem maiores retornos aos stakeholders, criar valor para os acionistas e, sobretudo, pela perspectiva de a empresa resultante desse processo conseguir um desempenho superior à soma individual das empresas envolvidas, bem como por proporcionar um crescimento rápido (JENSEN; RUBACK, 1983; BRADLEY; DESSAI; KIM, 1988; HEALY; PALEPU; RUBACK, 1992; CAMARGOS; BARBOSA, 2010; RAO-NICHOLSON; SALABER; CAO, 2016; HANIFI; VAHEDI, 2016; LI; LI; WANG, 2016; ZHONG, 2016).

Contudo, observa-se que as evidências sobre os efeitos das fusões e aquisições, principalmente associadas ao desempenho econômico-financeiro das empresas, ainda são controversas (BRADLEY, DESSAI; KIM, 1988; HEALY; PALEPU; RUBACK, 1992; GOSH, 2001; CAMARGOS; BARBOSA, 2010; BHABRA; HUANG, 2013). De acordo com Gugler, Mueller e Weichselbaumer (2012) e Li, Li e Wang (2016), apesar de haver diversas discussões empíricas, não há, ainda, um consenso sobre se as fusões e aquisições são lucrativas para as empresas adquirentes ou resultantes dessas combinações de negócios nos anos posteriores a realização dessas negociações.

Desta forma, considerando o crescente número de operações de fusões e aquisições ocorridas no cenário brasileiro e a necessidade do desenvolvimento de pesquisas que busquem desenvolver evidências acerca dos benefícios provocados por estas combinações de negócios para as empresas envolvidas, principalmente no que se refere ao desempenho econômico-financeiro após a efetivação dessas operações, surge o seguinte questionamento: quais foram os efeitos provocados pelas fusões e aquisições no desempenho econômico-financeiro das empresas brasileiras que realizaram essas combinações de negócios?

Para responder ao problema de pesquisa proposto, o objetivo desta pesquisa foi identificar os efeitos provocados pelas fusões e aquisições no desempenho econômico-financeiro das empresas brasileiras de capital aberto envolvidas nessas combinações de negócios. Este estudo justifica-se pela necessidade de analisar os impactos proporcionados pelas F\&As no desempenho de empresas brasileiras que realizaram esses tipos de combinações de negócios, buscando novas evidências a partir da utilização de variáveis, a exemplo do crescimento interno das empresas e por fusão e aquisição, do tipo de financiamento utilizado pelas firmas para financiar essas transações, entre outras. Dessa maneira, este trabalho contribui com o desenvolvimento da literatura associada ao tema, demonstrando, principalmente, os efeitos do crescimento por fusão $e$ aquisições e das modalidades de financiamento sobre o desempenho financeiro organizacional, visto serem escassos os estudos que examinam estas relações no cenário nacional e internacional.

\section{Revisão da Literatura}

Esta seção apresenta uma revisão da literatura acerca das características das fusões e aquisições, das teorias e hipóteses utilizadas e aplicadas a estas combinações de negócios, bem como dos principais estudos anteriores no âmbito nacional e internacional.

\subsection{Fusões e Aquisições}

As fusões são combinações de negócios em que duas ou mais empresas se unem para formar uma nova companhia. Já uma operação de aquisição caracteriza-se pela aquisição total ou parcial de uma companhia por outra ou por um grupo empresarial (TRICHES, 1996).

As operações de fusões e aquisições (F\&A) tiveram origem no final do século XVIII e início do 
século XIX, sendo impulsionadas pelo processo de concentração de capitais e reestruturação corporativa iniciada com a Revolução Industrial (CAMARGOS; BARBOSA, 2003). Segundo Nelson (1959) e Yaghoubi et al. (2016), foi nos Estados Unidos onde ocorreram as primeiras operações de fusões e aquisições no ano de 1887, sendo que a partir desse ano, essas combinações de negócios passaram a ocorrer em um número elevado, provocando um intenso volume dessas transações na economia norte-americana e no mercado de capitais. Desde esse período, já ocorreram seis ondas de fusões e aquisições, que vêm se espalhando por todo o mundo.

A primeira onda foi marcada pela formação de monopólios, a segunda por oligopólios, a terceira pela formação de conglomerados econômicos, a quarta por combinações não amigáveis e a quinta onda pela internacionalização dessas operações, sendo motivadas por fatores estratégicos e por sinergias, e a sexta onda, iniciada em 2003, está sendo marcada por um grande número de aquisições transnacionais (MITCHELL; MULHERIN, 1996; YAGHOUBI et al., 2016). De acordo com Gugler, Mueller e Weichselbaumer (2012), essas ondas de fusões e aquisições ocorridas nos Estados Unidos foram fortemente impulsionadas pelo desenvolvimento dos mercados de capitais, facilitando a realização dessas transações, sendo considerado um fator importante na disseminação dessas operações para os demais países industrializados.

No Brasil, após a crise econômica ocorrida no fim da década de 1980 e início da década de 1990, com o início do processo de abertura econômica do país, visando sua modernização, fez com que inúmeros grupos empresariais buscassem vender ou adquirir outras companhias para enfrentar os novos desafios decorrentes da globalização econômica (TRICHES, 1996). Desde então, a economia brasileira tem acompanhado a cada ano o aumento no número de F\&As. Entre os anos de 2005 e 2012 ocorreram mais de 5.011 transações, das quais 2.367 foram entre empresas nacionais e 2.644 foram do tipo crossborder, isto é, que envolveram empresas de outros países (KPMG, 2013). Segundo Wood Jr., Vasconcelos e Caldas (2004), as fusões e aquisições realizadas no mercado brasileiro apresentam interesses tipicamente estratégicos, visando à conquista de maior participação no mercado; ganhos operacionais; aumento na lucratividade; ampliação na rede de distribuição e logística; e operações que almejavam a obtenção de know-how corporativo e de práticas gerenciais e de mercado.

Além disso, a ocorrência de fusões e aquisições nos mercados emergentes tem se caracterizado pela busca de recursos estratégicos, novas tecnológias, talentos, canais de distribuição, recursos naturais, ou pela necessidade de companhias estrangerias expandirem suas atividades para esses países (LI; LI; WANG, 2016; HANIFI; VAHEDI, 2016).

Dessa maneira, observa-se que os processos de F\&As ocorridos tanto no âmbito internacional como nacional visam proporcionar as empresas envolvidas ganhos e aumento nos lucros, recursos estratégicos, expansão de atividades, bem como maior participação de mercado e ganhos operacionais (GUGLER; MUELLER; WEICHSELBAUMER, 2012; LI; LI; WANG, 2016; HANIFI; VAHEDI, 2016).

\subsection{Teoria e Hipóteses Aplicadas às Fusões e às Aquisições}

A literatura associada a fusões e aquisições ainda não está consolidada em uma teoria geral que lhe sirva de base, sendo que, segundo Yaghoubi et al. (2016), a maioria das proposições teóricas é utilizada para explicar os motivos e razões para essas combinações de negócios, encontrando respaldo nos diversos enfoques da Teoria da Firma (CAMARGOS; COUTINHO, 2005. YAGHOUBI et al., 2016).

Dentre os enfoques da Teoria da Firma, Firth (1980) aponta que a maioria das explicações para a realização de uma fusão e aquisição encontra alicerce na Teoria da Maximização dos Lucros da Firma e/ou na Teoria da Maximização da Utilidade Gerencial. Além dessas duas Teorias, Berkovitch e Narayanan (1993) afirmam que a Teoria da Agência e a Hipótese das Sinergias também podem ser utilizadas para explicar os motivos que levam uma empresa a realizar uma F\&A e os possíveis efeitos provocados no desempenho econômico-financeiro dessas companhias.

De acordo com Firth (1980), na visão da Teoria da Maximização dos Lucros da Firma, as forças do mercado competitivo levam os administradores a maximizarem o valor das companhias e a riqueza dos acionistas. Dessa forma, acredita-se que os dirigentes das firmas só buscam empreender projetos que gerem 
retorno econômico para a empresa e para os seus acionistas, isto é, que apresentem valor presente líquido positivo (FIRTH, 1980). Nesse caso, uma operação de combinação de negócio só acontecerá se resultar no aumento do lucro da firma e, consequentemente, no bem-estar dos seus acionistas, seja pelo aumento da lucratividade, pela criação de monopólio, sinergias ou, ainda, pela substituição de gestores ineficientes nas empresas adquiridas (MANNE, 1965; FIRTH, 1980).

Contudo, segundo $\mathrm{Ng}$ (1974), alguns críticos enfatizam que os preceitos da Teoria da Maximização dos Lucros da Firma, por ter sido desenvolvida a partir da concepção clássica de empresa, não se aplicam a moderna corporação, caracterizada principalmente pela separação entre propriedade e controle.

De acordo com Marris (1963), sob quaisquer condições, exceto em uma economia de concorrência perfeita, a maximização do lucro da firma é raramente perseguida e quando o tomador de decisão não é ao mesmo tempo o receptor dos lucros, essa motivação deixa de ser um objetivo primário, demonstrando que os desejos dos gestores desviam-se dos objetivos organizacionais. Ainda de acordo com o autor, apesar de alguns estudos apontarem que é o desejo dos administradores que aumenta o tamanho das empresas e, com isso, maximiza a taxa de crescimento das firmas sob seu comando, esses pressupostos não são necessariamente equivalentes porque os administradores poderiam buscar empregos em grandes empresas ou mesmo tornarem-se presidentes de grandes companhias, por exemplo, para receberem elevados salários e aumentar o seu poder. Assim, para Marris (1963), os administradores veem o crescimento das firmas como um dos melhores métodos para satisfazerem suas necessidades e ambições pessoais, buscando, assim, não somente aumentar seus salários, mas seu prestígio, poder, ou seja, buscam maximizar sua utilidade gerencial em detrimento da maximização dos lucros e da riqueza dos acionistas.

Dessa forma, com a separação entre a propriedade e controle, a maximização do lucro da firma deixa de ser a principal finalidade dos gestores, que passam a empregar os recursos da companhia com o objetivo de maximizar ainda mais sua utilidade gerencial (MARRIS, 1963). Nessa ótica, os administradores se utilizam de meios que garantam o aumento rápido de sua utilidade gerencial, sendo as operações de fusão $e$ aquisição um dos meios mais rápidos de potencializar o crescimento da companhia e atingir seus objetivos. Percebe-se, dessa maneira, que a realização de F\&As pode ser um meio dos dirigentes da corporação adquirente aumentarem seu próprio bem-estar, ainda que essas transações não se mostrem lucrativas e causem um impacto negativo no valor de mercado das ações da firma (MUELLER, 1969; FIRTH, 1980).

Segundo Jensen e Meckling (1976), a Teoria da Agência, noutra perspectiva, define essa relação entre os acionistas (principais) e os administradores (agentes) como um contrato no qual uma ou mais pessoas - 0 principal - contratam outra pessoa - o agente - para desempenhar alguma tarefa em seu favor, evolvendo a delegação de autoridade para a tomada de decisão pelo agente. Dessa forma, se ambas as partes agem buscando maximizar suas utilidades pessoas, de acordo com a Teoria da Agência existe uma boa razão para acreditar que o agente não agirá sempre no melhor interesse do principal. Tal fato pode-se dar em operações de fusões e aquisições em que os administradores buscam realizar essas operações para maximizar sua utilidade em detrimento da melhor utilização dos recursos na maximização dos resultados dos acionistas (BERKOVITCH; NARAYANAN, 1993).

Por outro lado, a Hipótese das Sinergias postula que a realização de uma combinação de negócios é motivada pela criação de ganhos a partir da melhor utilização dos ativos corporativos pela empresa adquirente ou pela nova companhia resultante da união empresarial, gerando, assim, mais riqueza para os acionistas dessas entidades. Assim, a Hipótese das Sinergias pressupõe que em processos de fusões e de aquisições só ocorrerão sinergias quando o valor das companhias combinadas for maior que a soma dos valores individuais das entidades (BRADLEY; DESSAI; KIM, 1988; SETH, SONG; PETTIT, 2000).

Segundo Damodaran (2005), as sinergias podem ser agrupadas em duas fontes: sinergias operacionais e sinergias financeiras. As sinergias operacionais afetam as operações da empresa combinada e incluem as economias de escala, aumento de eficiência, obtenção de poder de mercado, aumento no poder de fixação de preços e aumento no potencial dos ganhos, entre outras. Já as sinergias financeiras, por sua vez, incluem os benefícios fiscais, a capacidade de endividamento, a redução das taxas de financiamento, o excesso de 
fluxo de caixa livre gerado pela união das companhias após a combinação de negócios, entre outras (JENSEN; RUBACK, 1983; COOPELAND; WESTON; SHASTRI, 2005).

Desta forma, para a literatura (NIESTEN; JOLINK, 2015; RAO-NICHOLSON; SALABER; CAO, 2016; YAGHOUBI et al., 2016; BEULE; SELS, 2016; LI; WANG, 2016; HANIFI; VAHEDI, 2016) diversos enfoques teóricos são utilizados para explicar os motivos e as razões que levam os gestores a realizarem uma operação de fusão e aquisição, sendo estas combinações de negócios um dos eventos corporativos mais complexos e estratégico para as firmas maximizarem seus lucros, obterem sinergias ou para os administradores maximizarem sua utilidade.

A partir do exposto, pode-se dizer que os diversos enfoques teóricos apresentados sustentam que a realização de fusões e aquisições podem ocasionar mudanças no desempenho das companhias envolvidas nessas operações, seja aumentando a lucratividade das companhias e a riqueza dos acionistas, ou mesmo reduzindo sua rentabilidade, quando realizadas visando tão somente à maximização da utilidade gerencial.

\subsection{Estudos Anteriores}

A literatura aponta o estudo de Meeks (1977) como um dos primeiros realizados para investigar os impactos das F\&As no desempenho das empresas adquirentes ou resultantes das fusões no Reino Unido no período de 1964 a 1972, evidenciando que no ano da combinação de negócios houve um efeito positivo na lucratividade da firma adquirente, mas nos períodos seguintes a rentabilidade foi significantemente menor do que no primeiro ano da operação, sugerindo que as fusões e aquisições impactaram negativamente na lucratividade das companhias.

Ikeda e Doi (1983) investigaram o desempenho financeiro de companhias que realizaram fusões e aquisições no Japão no período de 1964 a 1975, demonstrando que o desempenho melhorava no terceiro e no quinto ano após a integração, sendo a lucratividade bastante elevada no quinto ano após a realização da operação.

Por meio da análise de regressão, Healy, Palepu e Ruback (1992) examinaram o desempenho pós-aquisição dos 50 maiores processos de fusões e aquisições ocorridos nos Estados Unidos no período de 1979 a 1984, revelando que as firmas combinadas apresentavam melhoria de produtividade de seus ativos em relação ao setor econômico em que estão inseridas, e que havia uma forte correlação positiva entre os retornos anormais das ações durante os anúncios e o desempenho operacional anormal das empresas após o processo de fusão.

O estudo de Switzer (1996) encontrou evidências que reforçam as descobertas de Healy, Palepu e Ruback (1992), demonstrando que as operações de fusões e aquisições realizadas pelas empresas americanas entre 1967 e 1987 provocaram melhorias no desempenho e sinergias foram geradas por estas combinações de negócios.

Por outro lado, Dickerson, Gibson e Tsakalotos (1997) reportaram que as F\&As realizadas por empresas do Reino Unido tiveram um efeito negativo no desempenho das companhias adquirentes e que o crescimento das firmas produzido pelas aquisições produzia uma baixa taxa de retorno dos ativos quando comparado ao retorno dos ativos produzidos pelo crescimento interno das organizações.

Ghosh (2001) buscou evidências que corroborassem com as descobertas de Healy, Palepu e Ruback (1992), equiparando as empresas de sua amostra de acordo com o desempenho e o tamanho para evitar que ocorressem vieses em suas análises. Os resultados indicam que não há evidências de que o desempenho das firmas melhora após as fusões e aquisições, porém observou-se um efeito positivo, no desempenho corporativo, das combinações financiadas por caixa em relação às financiadas por ações, como sugerido por estudos anteriores.

No Brasil, Matias e Pasin (2001) verificaram que os processos de fusões e aquisições realizadas entre 1995 e 1997 provocaram reduções nos custos e nas despesas, com consequente aumento na rentabilidade, sugerindo que estas combinações de negócios produziram sinergias para as empresas envolvidas.

Rocha, Iootty e Ferraz (2001) analisaram os efeitos dos processos de F\&A sobre o desempenho das empresas industriais adquiridas entre 1990 e 1997, reportando que não há evidencias de aumento na rentabilidade das empresas até dois anos após sua aquisição, bem como que as empresas privatizadas são as únicas em que o resultado parece ser positivo. 
Gugler et al. (2003) analisaram os efeitos das fusões ocorridas em diversos países do mundo comparando o desempenho das empresas combinadas com um grupo de controle de firmas não integradas, evidenciando que apesar de as fusões resultarem em aumentos significativos nos lucros, estas reduzem as vendas das empresas combinadas, sendo essas evidências semelhantes entre os países pesquisados. Observou-se, também, que não houve diferenças significativas entre os setores de atuação das empresas e, que em combinações do tipo conglomerado, a redução das vendas é maior do que as do tipo horizontal. Além disso, as evidências sugerem que o aumento nos lucros está ligado ao aumento no poder de mercado e no amento da eficiência organizacional.

Por sua vez, Camargos e Barbosa (2005; 2009, 2010) identificaram uma piora na situação financeira das companhias brasileiras envolvidas nestas combinações de negócios. Contudo, encontraram evidências de que as operações de fusões e aquisições geram sinergias para as empresas envolvidas, sendo que no segundo período de análise as empresas adquirentes apresentaram um maior potencial de gerar sinergias operacionais e gerenciais, e de melhorar a rentabilidade.

Colares e Borges (2011) avaliaram a relação entre os investimentos em fusões e aquisições em empresas brasileiras por meio de coligadas e controladas e as medidas de desempenho financeiro no ano de 2009, demonstrando que os investimentos em coligadas e controladas tiveram uma relação positiva de $8,8 \%$ sobre o retorno dos ativos (ROA). No entanto, verificou-se que os investimentos não possuem relação com o retorno sobre o patrimônio líquido (ROE), indicando pouca capacidade preditiva da variável.

Em outro estudo, Lau, Proimos e Wright (2008) analisaram o efeito das fusões no desempenho de empresas australianas, encontrando evidências de que essas operações melhoram o desempenho operacional das empresas que passaram por essas transações, obtendo alta lucratividade e fluxo de caixa, e maior eficiência após o processo de fusão.

Rani, Yadav e Jain (2013) investigaram o impacto das fusões e aquisições sobre o desempenho corpora- tivo de empresas indianas, demonstrando que houve uma melhora no desempenho das empresas após as combinações. Além disso, a aplicação do Método Du Pont indicou um aumento na margem de lucro operacional de longo prazo das empresas adquirentes, sugerindo que as companhias obtiveram maiores lucros por unidades de vendas líquidas pós-fusão.

Por outro lado, Bhabra e Huang (2013) não encontraram evidências de que o desempenho operacional das empresas chinesas adquirentes melhorou após os processos de fusões e aquisições. Nesse sentido, Hanifi e Vahedi (2006) mostraram que o desempenho das firmas-alvo não aumentaram significantemente após a combinação de negócio, sugerindo uma redução na performance dessas firmas se comparada ao período anterior ao da aquisição.

Rao-Nicholson, Salaber e Cao (2016) examinaram o desempenho de fusões e aquisições de empresas asiáticas entre 2001 e 2012, demostrando que, no período pré-crise internacional, certas características como o tamanho da firma-alvo, setor, operações transnacionais, aquisições por meio de caixa e operações amigáveis foram fatores positivos e determinantes para o desempenho das companhias que realizaram fusões e aquisições neste período. Porém, para operações realizadas durante o período da crise, tais variáveis não apresentaram relação com a performance das firmas após as F\&As.

Ahmamad et al. (2016) encontraram evidências de que a transferência e compartilhamento de conhecimento e a manutenção de funcionários nas empresas adquiridas por meio de fusões e aquisições transnacionais apresentam uma relação positiva com o desempenho dessas companhias após a efetivação das combinações de negócios.

Observa-se que os resultados reportados na literatura são diversos, não havendo um consenso quanto aos resultados reportados por estas pesquisas. No entanto, poucos trabalhos consideraram os possíveis efeitos do crescimento interno das empresas e do crescimento decorrente das F\&As, bem como das modalidades de financiamentos utilizadas pelas companhias para realizar essas combinações de negócios, conforme defendido por Dickerson, Gibson e Tsakalotos (1997) e Gosh (2001). 


\begin{tabular}{|c|c|c|c|c|}
\hline Autores/Ano & $\begin{array}{l}\text { País de } \\
\text { estudo }\end{array}$ & $\begin{array}{c}\text { Período } \\
\text { investigado }\end{array}$ & $\begin{array}{l}\text { Variáveis } \\
\text { consideradas }\end{array}$ & Resultados observados \\
\hline Meeks (1977) & $\begin{array}{l}\text { Reino } \\
\text { Unido }\end{array}$ & 1964-1972 & Lucratividade & $\begin{array}{l}\text { No ano da integração houve um efeito positivo na } \\
\text { lucratividade, mas, nos períodos seguintes, a rentabilidade foi } \\
\text { significantemente menor do que o primeiro ano da operação. }\end{array}$ \\
\hline $\begin{array}{l}\text { Ikeda e Doi } \\
\quad(1983)\end{array}$ & Japão & 1964 a 1975 & $\begin{array}{l}\text { Desempenho } \\
\text { financeiro; } \\
\text { lucratividade. }\end{array}$ & $\begin{array}{l}\text { O desempenho das companhias melhorou no terceiro } \\
\text { e quinto ano após a integração, sendo a lucratividade } \\
\text { elevada no quinto ano após a operação. }\end{array}$ \\
\hline $\begin{array}{l}\text { Healyet al. } \\
\text { (1992) }\end{array}$ & $\begin{array}{l}\text { Estados } \\
\text { Unidos }\end{array}$ & 1979 a 1984 & $\begin{array}{l}\text { Desempenho } \\
\text { operacional; } \\
\text { ROA }\end{array}$ & $\begin{array}{l}\text { Constatou-se melhoria de produtividade dos ativos das firmas, } \\
\text { e uma forte correlação positiva entre os retornos anormais das } \\
\text { ações e a performance operacional após o processo de fusão. }\end{array}$ \\
\hline Switzer (1996) & $\begin{array}{l}\text { Estados } \\
\text { Unidos }\end{array}$ & $1967-1987$ & Fluxo de Caixa & $\begin{array}{l}\text { A performance melhorou após a combinação, bem como } \\
\text { houve melhorias estatisticamente significantes na margem } \\
\text { operacional do fluxo de caixa e na utilização dos ativos. }\end{array}$ \\
\hline $\begin{array}{l}\text { Dickerson, } \\
\text { Gibson e } \\
\text { Tsakalotos (1997) }\end{array}$ & $\begin{array}{l}\text { Reino } \\
\text { Unido }\end{array}$ & $1960-1970$ & $\mathrm{ROA}$ & $\begin{array}{l}\text { As F\&As provocaram um efeito negativo no desempenho das } \\
\text { companhias. O retorno provocado pelo crescimento interno das } \\
\text { companhias foi superior ao decorrente das fusões e aquisições. }\end{array}$ \\
\hline Ghosh (2001) & $\begin{array}{l}\text { Estados } \\
\text { Unidos }\end{array}$ & 1981-1995 & Fluxo de Caixa & $\begin{array}{l}\text { Não há evidências de que a performance das firmas melhora após } \\
\text { as fusões e aquisições, porém observou-se um efeito positivo das } \\
\text { combinações financiadas por caixa no desempenho corporativo. }\end{array}$ \\
\hline $\begin{array}{l}\text { Matias e Pasin } \\
\quad(2001)\end{array}$ & Brasil & 1995-1997 & Rentabilidade & $\begin{array}{l}\text { As sinergias ocorridas foram resultantes da integração entre as } \\
\text { empresas e da melhor gestão administrativa nos processos de F\&A. }\end{array}$ \\
\hline $\begin{array}{l}\text { Rocha, loottye } \\
\text { Ferraz (2001) }\end{array}$ & Brasil & 1990-1997 & Rentabilidade & $\begin{array}{l}\text { Não há diferenças significativas no desempenho } \\
\text { econômico-financeiro após a F\&A. }\end{array}$ \\
\hline $\begin{array}{l}\text { Gugleret al. } \\
\text { (2003) }\end{array}$ & $\begin{array}{l}\text { Vários } \\
\text { países }\end{array}$ & 1981-1998 & Lucro; vendas & $\begin{array}{l}\text { Houve aumentos nos lucros, redução nas vendas, sendo que } \\
\text { nas combinações do tipo conglomerado a redução das vendas } \\
\text { é maior, e o aumento nos lucros está ligado ao aumento } \\
\text { no poder de mercado e da eficiência organizacional. }\end{array}$ \\
\hline $\begin{array}{l}\text { Lau, Proimos e } \\
\text { Wright (2008) }\end{array}$ & Austrália & 1999-2004 & $\begin{array}{l}\text { ROE; ROA; } \\
\text { EBIT }\end{array}$ & $\begin{array}{l}\text { O desempenho operacional das empresas que passaram por } \\
\text { essas transações melhorou, obtendo alta lucratividade e fluxo } \\
\text { de caixa, e maior eficiência após o processo de fusão. }\end{array}$ \\
\hline $\begin{array}{c}\text { Camargos } \\
\text { e Barbosa } \\
(2005,2009,2010)\end{array}$ & Brasil & $\begin{array}{l}1995-1999 \\
1996-2004\end{array}$ & $\mathrm{ROA} ; \mathrm{ROE}$ & $\begin{array}{l}\text { Identificaram uma redução no desempenho das companhias. } \\
\text { Obtiveram evidências da criação de sinergias gerenciais } \\
\text { e operacionais após as combinações de negócios. }\end{array}$ \\
\hline $\begin{array}{l}\text { Colares e } \\
\text { Borges (2011) }\end{array}$ & Brasil & 2009 & $\mathrm{ROA} ; \mathrm{ROE}$ & $\begin{array}{l}\text { Os investimentos apresentaram um aumento no ROA de } 8,8 \% \text { após } \\
\text { as operações, porém o ROE apresentou pouca capacidade preditiva. }\end{array}$ \\
\hline $\begin{array}{l}\text { Rani, Yadav e } \\
\text { Jain (2013) }\end{array}$ & Índia & 2003-2008 & $\begin{array}{l}\text { Fluxo de Caixa } \\
\text { Operacional }\end{array}$ & $\begin{array}{l}\text { Houve melhora no desempenho das empresas. Além } \\
\text { disso, a aplicação do DuPont Model indicou um aumento } \\
\text { na margem de lucro operacional no longo prazo. }\end{array}$ \\
\hline $\begin{array}{c}\text { Bhabra e } \\
\text { Huang (2013) }\end{array}$ & China & $1997-2007$ & $\mathrm{ROA} ; \mathrm{ROE}$ & $\begin{array}{l}\text { Não há evidências de que o desempenho operacional das empresas } \\
\text { adquirentes melhorou após os processos de fusões e aquisições. }\end{array}$ \\
\hline $\begin{array}{l}\text { Hanifi e Vahedi } \\
\quad(2016)\end{array}$ & Irã & $2003-2011$ & $\mathrm{ROA} ; \mathrm{ROE}$ & $\begin{array}{l}\text { O desempenho das firmas-alvo não aumentou significantemente após } \\
\text { a combinação de negócio, sugerindo uma redução na performance } \\
\text { dessas firmas se comparada ao período anterior ao da aquisição }\end{array}$ \\
\hline $\begin{array}{l}\text { Rao-Nicholson, } \\
\text { Salaber e } \\
\text { Cao (2016) }\end{array}$ & $\begin{array}{l}\text { Países } \\
\text { Asiáticos }\end{array}$ & 2001-2012 & $\begin{array}{l}\text { ROA; } \\
\text { lucratividade; } \\
\text { margem líquida }\end{array}$ & $\begin{array}{l}\text { O tamanho da firma-alvo, setor, operações transnacionais, tipo } \\
\text { de financiamento e operações amigáveis foram fatores positivos } \\
\text { e determinantes para o desempenho das companhias que } \\
\text { realizaram fusões e aquisições antes da crise internacional, mas para } \\
\text { operações realizadas durante o período da crise, tais variáveis não } \\
\text { apresentaram relação com a performance das firmas após as F\&As. }\end{array}$ \\
\hline $\begin{array}{l}\text { Ahmamad et } \\
\text { al. (2016) }\end{array}$ & $\begin{array}{l}\text { Reino } \\
\text { Unido }\end{array}$ & $2000-2004$ & $\begin{array}{l}\text { Lucratividade, } \\
\text { margem } \\
\text { líquida, } \mathrm{ROI}\end{array}$ & $\begin{array}{l}\text { A transferência e compartilhamento de conhecimento e a manutenção } \\
\text { de funcionários nas empresas adquiridas por meio de F\&A } \\
\text { transnacionais apresentam uma relação positiva com o desempenho } \\
\text { dessas companhias após a efetivação das combinações de negócios. }\end{array}$ \\
\hline
\end{tabular}

Quadro 1: Resumo das evidências empíricas

Fonte: Elaborado pelos autores deste artigo 
De acordo com o exposto no Quadro 1, observa-se que as evidências sobre os efeitos das fusões $e$ aquisições no desempenho econômico-financeiro das empresas envolvidas nessas combinações de negócios ainda são conflitantes, evidenciado benefícios e prejuízos no desempenho das empresas após a realização dessas operações.

\section{Metodologia}

Nesta seção apresenta-se como foram selecionadas a população e a amostra da pesquisa e como foi realizada a coleta dos dados. Além disso, expõe-se a descrição dos modelos econométricos e a especificação (técnica) econométrica para avaliar a relação entre as variáveis estudadas.

\subsection{População, Amostra e Dados da Pesquisa}

A população objeto desta pesquisa foi composta pelas companhias brasileiras de capital aberto listadas na Bolsa de Valores, Mercadorias e Futuros do Estado de São Paulo (BM\&FBovespa) e que tenham realizado operações de fusões e aquisições no período considerado (entre o quarto trimestre de 2008 e o terceiro trimestre de 2012). Esse período foi definido devido à adoção do padrão internacional de contabilidade pelas empresas brasileiras a partir do ano de 2008, visto que a comparação com períodos anteriores poderia prejudicar a análise dos dados e distorcer os resultados apresentados, restringindo o número de períodos para quatro trimestres antes e após a efetivação da combinação de negócio.

Para a identificação das empresas que realizaram fusões e aquisições no período investigado foram utilizadas as informações fornecidas pela Associação Brasileira das Entidades dos Mercados Financeiros e de Capitais (ANBIMA), que publica informes sobre os processos de fusões e aquisições ocorridos no Brasil. De acordo com informações disponibilizadas pela ANBIMA (2013), entre os anos de 2008 e 2011 foram efetivadas 445 operações de fusões e aquisições no mercado brasileiro, sendo 144 transações efetuadas por 114 companhias de capital aberto e o restante por firmas de capital fechado.
A amostra desta pesquisa caracteriza-se como não probabilística intencional, uma vez que não foi empregada qualquer técnica estatística para sua escolha, mas a escolha das firmas participantes deu-se a partir de determinados critérios (MARTINS; THEÓPHILO, 2009). Os critérios utilizados para a seleção da amostra foram os seguintes: (1) ser uma companhia com ações negociadas na BM\&FBovespa; (2) envolver companhias não financeiras; (3) ter o Brasil como país sede; (4) ter realizado operações de fusões e aquisições no período investigado; (5) não ter participado de combinações de negócios entre empresas de um mesmo grupo empresarial (aquisição reversa); e (6) ter dados disponíveis para análise.

Assim, a amostra final da pesquisa foi composta por 53 empresas de capital aberto que realizaram 70 operações de fusões e aquisições entre o quarto trimestre de 2008 e terceiro trimestre de 2012, sendo 1 fusão e 69 de aquisições.

Os dados utilizados na análise desta pesquisa foram obtidos do banco de dados do Economática ${ }^{\circledR}$, no sítio da BM\&FBovespa, nas demonstrações contábeis e nos demais relatórios econômico-financeiros disponibilizados pelas companhias nos seus sítios na Internet. Para a obtenção das variáveis investigadas (dependentes e explicativas) consideraram-se apenas as demonstrações contábeis não consolidadas das companhias, pois se buscou analisar o efeito das F\&As sobre o desempenho de determinada companhia e não do grupo empresarial ao qual ela pertence.

\subsection{Descrições dos Modelos Econométricos}

De acordo com a literatura, para avaliar o efeito das fusões e aquisições sobre o desempenho econômico-financeiro das companhias que realizaram essas combinações de negócios, apresenta-se necessária a aplicação de modelos que permitam avaliar o desempenho das empresas após as F\&As, que possam captar o efeito de variáveis, a exemplo do tipo de financiamento e do crescimento por fusão e aquisição, e que permitam analisar a persistência no desempenho das companhias após as combinações de negócios (HEALY; PALEPU; RUBACK, 1992; DICKERSON; GIBSON; TSAKALOTOS, 1997; GOSH, 2001). Dessa forma, foi adaptado o modelo proposto por Dickerson, Gibson e Tsakalotos (1997), visto que 
ele apresenta características que podem atender ao objetivo propostos por este trabalho.

O modelo proposto por Dickerson, Gibson e Tsakalotos (1997) parte do pressuposto que o desempenho das companhias é dinâmico, sendo necessário avaliar a persistência na performance das companhias após a combinação de negócios, conforme Equação 1:

$\pi_{i t}=\beta_{0}+\beta_{1} \pi_{i p r e}+\beta_{2} C F A_{i t}+\beta_{3} C I_{i t}+\beta_{4} A c ̧ \tilde{e} e s_{i t}+\beta_{5}$ Caixa $_{i t}+\beta_{6}$ Divid $_{i t}+$ $\beta_{7}$ Misto $_{i t}+\beta_{8}$ Setor $_{i t}+\beta_{9}$ Tam $_{i t}+\beta_{10}$ Endiv $_{i t}+\beta_{11} N F A_{i t}+\beta_{12} T F A_{i t}+\varepsilon_{i t}(1)$

Em que,

- Tité o desempenho econômico-financeiro da companhia i no período posterior à operação de fusão e aquisição, medido pelo retorno dos ativos (ROA), retorno sobre o patrimônio líquido (ROE) e o lucro operacional ou EBIT;

- tipre é o desempenho econômico-financeiro da empresa $i$ no período anterior à operação de fusão e aquisição, medido pelo retorno dos ativos (ROA), retorno sobre o patrimônio líquido (ROE) e o lucro operacional ou EBIT;

- CFAit é o crescimento por fusão e aquisição da empresa $i$ no período $t$; mensurado pela relação entre os ativos adquiridos e o ativo total de cada companhia no período anterior a combinação de negócio;

- Clit é o crescimento interno da empresa $i$ no período $t$, mensurado pela relação entre aumento nos ativos e variação nos lucros retidos;

- Açõesit é uma variável dummy que assume valor igual a 1 se a F\&A foi realizada mediante a utilização de ações da firma, e valor 0 caso contrário;

- Caixait é uma variável dummy que assume valor igual a 1 se a combinação de negócios foi realizada com dinheiro, e valor 0 caso contrário;

- Dividit é uma variável dummy que assume valor igual a 1 se a combinação de negócios foi financiada por meio de dívidas, e valor 0 caso contrário;

- Mistoit é uma variável dummy que assume valor igual a 1 se a F\&A foi financiada por mais de uma fonte de recursos, e valor 0 caso contrário;

- Setorit é uma variável dummy que assume valor igual a 1 se a F\&A foi realizada entre empresas de mesmo setor econômico, e valor 0 caso contrário;

- Tamit é o tamanho da empresa $i$ no período $t$, medido pelo logaritmo natural dos ativos;

- Endivit é o endividamento da empresa $i$ no período $t$; mensurado pela relação entre as dívidas líquidas (passivo oneroso) com o patrimônio líquido de cada firma;

- NFAit é uma variável dummy que assume valor igual a 1 se a companhia $i$ realizou mais de uma operação de F\&A no período analisado, e valor igual a 0 , caso contrário;

- TipoFAit é uma variável dummy que assume valor igual a 1 se a fusão e/ou aquisição foi do tipo horizontal ou vertical, e valor 0 caso contrário; $e$

- cit é o termo de erro da regressão.

A Equação 1 apresenta que o desempenho das empresas após as fusões e aquisições é explicado pela performance anterior das companhias, pelo tipo de crescimento (interno e por F\&A), pelo tipo de financiamento utilizado, pelo setor econômico relacionado, pelo tamanho, pelo nível de endividamento, pelo tipo de F\&A e pelo número de combinações de negócios, sendo a relação entre a variável dependente e as explicativas verificadas mediante o coeficiente e pelo sinal do coeficiente de cada variável explicativa.

De acordo com Dickerson, Gibson e Tsakalotos (1997), por meio do coeficiente da variável desempenho anterior ( $\beta \pi$ ipre), pode-se capturar o grau de persistência no desempenho das companhias após as operações de fusões e aquisições, sendo que, de acordo com a literatura, espera-se que o desempenho das empresas seja persistente após as F\&As.

A partir da Equação 1, foram estimados três modelos econométricos, sendo que para cada estimação aplicou-se uma variável explicada diferente. O Modelo 1 tem como variável dependente o retorno sobre o patrimônio líquido (ROE), no Modelo 2 foi utilizado o retorno dos ativos (ROA) e no Modelo 3 aplicou-se os lucros antes dos juros e dos impostos (EBIT). As variáveis explicativas selecionadas foram às mesmas para os três modelos.

Dessa forma, pela Equação 1 é possível avaliar a persistência no desempenho das empresas após a efetivação das fusões e aquisições, bem como o efeito provocado pelo tipo de financiamento, pelo tipo de 
crescimento, bem como pelas demais variáveis, conforme incialmente estabelecido. Ademais, também se buscou a partir da variável setor econômico e tamanho, captar possíveis sinergias provenientes das combinações de negócios, conforme previsto pela Hipótese das Sinergias. As variáveis independentes foram calculadas conforme o Quadro 1:

\begin{tabular}{|c|c|c|c|}
\hline VARIÁVEL & DESCRIÇÃo & Cálculo & $\begin{array}{c}\text { SinAL } \\
\text { ESPERADO }\end{array}$ \\
\hline$\pi_{\text {ipre }}$ & $\begin{array}{c}\text { Desempenho } \\
\text { anterior } \\
\text { as F\&As }\end{array}$ & $\begin{array}{l}\text { Retorno dos ativos (EBIT/ } \\
\text { AT); Retorno sobre o } \\
\text { patrimônio líquido (LL/ } \\
\text { (PL - LL); Lucro antes } \\
\text { dos juros e dos tributos } \\
\text { sobre o lucro (EBIT) }\end{array}$ & + \\
\hline CFA & $\begin{array}{c}\text { Crescimento } \\
\text { por F\&A }\end{array}$ & $\begin{array}{l}\text { Relação entre os ativos } \\
\text { adquiridos e o ativo } \\
\text { total de cada companhia } \\
\text { antes da combinação } \\
\text { de negócios (AA/AT) }\end{array}$ & + \\
\hline $\mathrm{CI}$ & $\begin{array}{l}\text { Crescimento } \\
\text { interno das } \\
\text { empresas }\end{array}$ & $\begin{array}{l}\text { Mensurado pela } \\
\text { relação entre aumento } \\
\text { nos ativos e variação } \\
\text { nos lucros retidos; }\end{array}$ & + \\
\hline Ações & $\begin{array}{l}\text { Operações } \\
\text { financiadas } \\
\text { por meio } \\
\text { de ações }\end{array}$ & $\begin{array}{l}\text { Variável dummy de valor } \\
\text { igual a } 1 \text { se a operação } \\
\text { for financiada por ações, } \\
\text { e valor } 0 \text { caso contrário }\end{array}$ & - \\
\hline Caixa & $\begin{array}{l}\text { Operações } \\
\text { financiadas } \\
\text { por caixa } \\
\text { (dinheiro) }\end{array}$ & $\begin{array}{l}\text { Variável dummy de valor } \\
\text { igual a } 1 \text { se a operação } \\
\text { for financiada por ações, } \\
\text { e valor } 0 \text { caso contrário }\end{array}$ & + \\
\hline Divid & $\begin{array}{l}\text { Operações } \\
\text { financiadas } \\
\text { por dívidas }\end{array}$ & $\begin{array}{l}\text { Variável dummy de valor } \\
\text { igual a } 1 \text { se a operação } \\
\text { for financiada por ações, } \\
\text { e valor } 0 \text { caso contrário }\end{array}$ & - \\
\hline Misto & $\begin{array}{l}\text { Operações } \\
\text { financiadas } \\
\text { por mais } \\
\text { de um tipo } \\
\text { de recurso }\end{array}$ & $\begin{array}{l}\text { Variável dummy de valor } \\
\text { igual a } 1 \text { se a operação } \\
\text { for financiada por ações, } \\
\text { e valor } 0 \text { caso contrário }\end{array}$ & $+/-$ \\
\hline Setor & $\begin{array}{l}\text { Setor } \\
\text { econômico } \\
\text { relacionado }\end{array}$ & $\begin{array}{l}\text { Variável dummy de valor } \\
\text { igual a } 1 \text { se a operação } \\
\text { for financiada por ações, } \\
\text { e valor } 0 \text { caso contrário }\end{array}$ & + \\
\hline Tam & $\begin{array}{l}\text { Tamanho } \\
\text { das } \\
\text { companhias }\end{array}$ & $\begin{array}{l}\text { Logaritmo natural } \\
\text { do Ativo do Total } \\
\text { das companhias }\end{array}$ & + \\
\hline Endiv & $\begin{array}{l}\text { Nível de } \\
\text { endivida- } \\
\text { mento das } \\
\text { companhias }\end{array}$ & $\begin{array}{l}\text { Mensurado pela relação } \\
\text { entre as dívidas líquidas } \\
\text { (passivo oneroso) com } \\
\text { o patrimônio líquido } \\
\text { de cada firma; }\end{array}$ & - \\
\hline
\end{tabular}

\begin{tabular}{|c|c|c|c|}
\hline NFA & $\begin{array}{l}\text { Número } \\
\text { de fusões e } \\
\text { aquisições } \\
\text { realizadas }\end{array}$ & $\begin{array}{l}\text { Variável dummy que } \\
\text { assume valor igual a } 1 \text { se } \\
\text { a companhia i realizou } \\
\text { mais de uma operação } \\
\text { de F\&A no período } \\
\text { analisado, e valor igual } \\
\text { a } 0 \text {, caso contrário; }\end{array}$ & + \\
\hline TFA & $\begin{array}{c}\text { Tipo de } \\
\text { fusão e } \\
\text { aquisição }\end{array}$ & $\begin{array}{l}\text { Variável dummy que } \\
\text { assume valor igual } \\
\text { a } 1 \text { se a fusão e/ou } \\
\text { aquisição foi do tipo } \\
\text { horizontal ou vertical, e } \\
\text { valor } 0 \text { caso contrário }\end{array}$ & + \\
\hline
\end{tabular}

Quadro 1: Definição das variáveis

Fonte: Elaborado pelos autores deste artigo

Assim, a partir das variáveis independentes apresentadas no Quadro 1, objetiva-se identificar o efeito provocado pelas fusões e aquisições no desempenho econômico-financeiro das empresas brasileiras que realizaram essas combinações de negócios no período investigado.

\subsection{Especificações do Modelo de Regressão}

O modelo econométrico utilizado neste trabalho teve como base a técnica de dados em painel, que combina dados seccionais e temporais, na forma dinâmica. A utilização de dados em painel permite a análise das mesmas empresas em vários períodos distintos, o que possibilita uma análise dinâmica do relacionamento entre as variáveis, podendo o painel ser balanceado ou desbalanceado (WOOLDRIDGE, 2002).

Para estimação dos modelos oriundos da Equação 1, utilizou-se o Método dos Momentos Generalizados-Sistema (MMG-Sistema) proposto, inicialmente, por Arellano e Bond (1991) e, posteriormente, aperfeiçoado por Arellano e Bover (1995) e Blundell e Bond (1998). Segundo os autores, a estimação dos modelos oriundos da Equação 1 pelas técnicas tradicionais seriam enviesados e inconsistentes, devido à presença dos efeitos individuais não observáveis dos indivíduos, juntamente com a variável dependente defasada, no lado direito da equação, bem como a provável endogeneidade das variáveis explicativas. Nesse caso, a endogeneidade no lado direito deve ser tratada para evitar um possível viés gerado por problema de simul- 
taneidade (ARELLANO; BOND, 1991; ARELLANO; BOVER, 1995; BLUNDELL; BOND, 1998).

O Método dos Momentos Generalizados-Sistema combina o conjunto de equações em diferença, com o conjunto de equação em nível, para reduzir esse problema de viés. Para as equações em diferenças, o conjunto de instrumentos é a utilização dos valores da variável defasada em um ou mais períodos ou em dois ou mais períodos, caso os primeiros instrumentos não sejam válidos. Já para a regressão em nível, os instrumentos apropriados são as diferenças defasadas das respectivas variáveis (ARELLANO; BOND, 1991; ARELLANO; BOVER, 1995; BLUNDELL; BOND, 1998).

Por fim, para avaliar a robustez e consistência do modelo foram aplicados os testes de Sargan e de Hansen, cuja hipótese nula é a de que os instrumentos não são correlacionados com os resíduos. Além disso, como se supõe incialmente, que os resíduos da regressão não sejam correlacionados, é feito um teste de correlação serial de primeira ordem e outro de segunda ordem sobre os erros em primeira diferença. Espera-se que esses erros sejam correlacionados em primeira ordem, mas não auto correlacionados em segunda ordem (ARELLANO; BOND, 1991; ROODMAN, 2009).

\section{Resultados}

Esta seção expõe os principais resultados da pesquisa, estimados por meio de três modelos econométricos, demonstrando as relações entre as variáveis investigadas, bem como os cotejando com as evidências reportadas em outras pesquisas.

\subsection{Análise Econométrica}

Os resultados das regressões foram estimados a partir da Equação 1. A Tabela 1 apresenta os resultados da estimação através do Modelo dos Momentos Generalizados-Sistema (MMG-Sistema), considerando o desempenho econômico-financeiro das companhias após as operações de fusões e aquisições, medido pelas proxies ROApt, ROEpt e EBITpt. As variáveis explicativas utilizadas para estimação foram: o crescimento por fusão e aquisição (CFA); o crescimento interno das companhias (CI); o tipo de financiamento utilizado para realização das operações de fusões e aquisições (variáveis dummies: Ações, Caixa, Divid e Misto); setor econômico relacionado (Setor); tamanho das empresas (Tam); endividamento das firmas (Endiv); número de F\&As (NFA); e pelo tipo de Fusão e Aquisição (TipoFA).

Inicialmente, mediante a estatística VIF, constatou-se que as variáveis NFA e TipoFA apresentaram problema de multicolinearidade, atingindo uma estatística de valor superior a 10. Nesse caso, optou-se por excluir essas variáveis, uma vez que a estimação com a presença desses regressores poderia prejudicar o entendimento do real efeito das variáveis independentes sobre as variáveis explicadas (BROOKS, 2008).

Para verificar a consistência dos estimadores dos modelos MMG-Sistema, aplicaram-se alguns testes. O teste de Sargan e o teste de Hansen foram utilizados para verificar se os instrumentos utilizados foram consistentes e se os instrumentos adicionais requeridos pelos modelos foram válidos. De acordo com as estatísticas dos testes para o Modelo 1 todos os instrumentos são válidos. Já para os Modelos 2 e 3, apenas pelo teste de Hansen, estimado com erros-padrões robustos, mostrou que os instrumentos eram válidos.

Aplicou-se, ainda, o teste de Arellano e Bond (1991) para avaliar a existência de autocorrelação de primeira e segunda ordem nos termos do erro. Segundo Arellano e Bond (1991), a ausência de autocorrelação de segunda ordem é primordial para a consistência do estimador do MMG. As estatísticas revelam que os estimadores de segunda ordem para os três modelos não apresentam autocorrelação, indicando que os estimadores dos modelos são consistentes, conforme Tabela 1. 
Tabela 1: Resultados das estimações pelo modelo de painel dinâmico

\begin{tabular}{|c|c|c|c|c|c|c|c|}
\hline \multirow{2}{*}{ VARIÁVEIS } & \multirow{2}{*}{$\begin{array}{c}\text { SinAL } \\
\text { ESPERADO }\end{array}$} & \multicolumn{2}{|c|}{ MODELO $\mathbf{1}-\mathbf{R O E}_{P T}$} & \multicolumn{2}{|c|}{ MODELO 2 - ROA } & \multicolumn{2}{|c|}{ MODELO 3 - EBIT } \\
\hline & & Coeficiente & VALOR-P & CoEficiente & VALOR-P & Coeficiente & VALOR-P \\
\hline $\mathrm{ROE}_{p r e} / \mathrm{ROA}_{p r e} / \mathrm{EBIT}_{\text {pre }}$ & + & 0,0984955 & $0,003^{* * * *}$ & 0,1233131 & $0,000 * * *$ & 0,0882228 & $0,028 * *$ \\
\hline CFA & + & $-0,0169496$ & $0,047 * *$ & $-0,0062211$ & 0,152 & $-0,0099629$ & $0,031^{* * *}$ \\
\hline $\mathrm{CI}$ & + & 0,6241767 & $0,000 * * *$ & 0,3575761 & $0,010 * *$ & 0,2612724 & 0,170 \\
\hline Ações & + & 0,0019005 & 0,907 & $-0,0044573$ & 0,523 & $-0,0064299$ & 0,256 \\
\hline Caixa & + & $-0,0185388$ & 0,236 & $-0,0108120$ & 0,079 & $-0,0072372$ & 0,230 \\
\hline Divid & - & 0,0020532 & 0,943 & 0,0002935 & 0,964 & 0,0039120 & 0,208 \\
\hline Misto & $+/-$ & $-0,0329221$ & $0,045^{* *}$ & $-0,0089341$ & 0,224 & $-0,0010116$ & 0,916 \\
\hline Setor & + & 0,0085199 & 0,542 & 0,0024492 & 0,591 & 0,0037329 & 0,421 \\
\hline Tam & + & 0,0082942 & $0,031 * *$ & 0,0037222 & 0,265 & 0,0053825 & 0,186 \\
\hline Endiv & - & $-0,0143252$ & $0,000 * * *$ & $-0,0093931$ & $0,005^{* *}$ & $-0,0057112$ & 0,082 \\
\hline \multirow[t]{3}{*}{ Constante } & & $-0,0239945$ & 0,366 & $-0,0065710$ & 0,784 & $-0,0149244$ & 0,588 \\
\hline & & \multicolumn{2}{|c|}{$\begin{array}{l}F(10,201)=13,78 \\
\text { Prob. }>F=0,000\end{array}$} & \multicolumn{2}{|c|}{$\begin{array}{l}F(10,201)=13,42 \\
\text { Prob. }>F=0,000\end{array}$} & \multicolumn{2}{|c|}{$\begin{array}{l}F(12,52)=6,60 \\
\text { Prob. }>F=0,000\end{array}$} \\
\hline & & \multicolumn{2}{|c|}{$\begin{array}{c}\mathrm{N}^{\circ} \text { Obs.: } 212 \\
\mathrm{~N}^{\circ} \text { de Grupos: } 53 \\
\mathrm{~N}^{\circ} \text { Instrumentos: } 35\end{array}$} & \multicolumn{2}{|c|}{$\begin{array}{c}\mathrm{N}^{\circ} \text { de Obs.: } 212 \\
\mathrm{~N}^{\circ} \text { de grupos: } 53 \\
\mathrm{~N}^{\circ} \text { instrumentos: } 35\end{array}$} & \multicolumn{2}{|c|}{$\begin{array}{c}\mathrm{N}^{\circ} \text { de Obs.: } 212 \\
\mathrm{~N}^{\circ} \text { de grupos: } 53 \\
\mathrm{~N}^{\circ} \text { instrumentos: } 35\end{array}$} \\
\hline \multicolumn{2}{|c|}{$\begin{array}{l}\mathrm{H}_{0} \text { : Ausência de autocorrelação } \\
\text { nos resíduos de primeira ordem }\end{array}$} & \multicolumn{2}{|c|}{$\begin{array}{c}Z=-1,95 \\
\text { Prob. }>Z=0,051\end{array}$} & \multicolumn{2}{|c|}{$\begin{array}{c}Z=-1,27 \\
\text { Prob. }>Z=0,206\end{array}$} & \multicolumn{2}{|c|}{$\begin{array}{c}Z=-2,22 \\
\text { Prob. }>Z=0,026\end{array}$} \\
\hline \multicolumn{2}{|c|}{$\begin{array}{l}\mathrm{H}_{0} \text { : Ausência de autocorrelação } \\
\text { nos resíduos de segunda ordem }\end{array}$} & \multicolumn{2}{|c|}{$\begin{array}{c}Z=-1,67 \\
\text { Prob. }>Z=0,094\end{array}$} & \multicolumn{2}{|c|}{$\begin{array}{c}Z=-0,96 \\
\text { Prob. }>Z=0,338\end{array}$} & \multicolumn{2}{|c|}{$\begin{array}{c}Z=-0,46 \\
\text { Prob. }>Z=0,647\end{array}$} \\
\hline \multicolumn{2}{|c|}{ Teste de Sargan } & \multicolumn{2}{|c|}{$\begin{array}{c}\text { Chi2 }=32,24 \\
\text { Prob. }>\text { Chi2 }=0,121\end{array}$} & \multicolumn{2}{|c|}{$\begin{array}{c}\text { Chi } 2=100,75 \\
\text { Prob. }>\text { Chi } 2=0,000\end{array}$} & \multicolumn{2}{|c|}{$\begin{array}{c}\text { Chi } 2=57,66 \\
\text { Prob. }>\text { Chi } 2=0,000\end{array}$} \\
\hline \multicolumn{2}{|c|}{ Teste de Hansen } & \multicolumn{2}{|c|}{$\begin{array}{c}\text { Chi2 }=20,66 \\
\text { Prob. }>\text { Chi2 }=0,898\end{array}$} & \multicolumn{2}{|c|}{$\begin{array}{c}\text { Chi } 2=20,17 \\
\text { Prob. }>\text { Chi2 }=0,687\end{array}$} & \multicolumn{2}{|c|}{$\begin{array}{c}\text { Chi } 2=20,17 \\
\text { Prob. }>\text { Chi } 2=0,687\end{array}$} \\
\hline
\end{tabular}

Nota: (a) Significância: ***Estatisticamente significante a 1\%; **Estatisticamente significante a 5\%.

Fonte: Dados da pesquisa

Os resultados, evidenciados na Tabela 1, sugerem que o desempenho econômico-financeiro das empresas foi persistente ao longo do período analisado, conforme coeficiente das variáveis ROEpre, ROApre e EBITpre, sendo positivo e estatisticamente significante ao nível de $1 \%$ nos Modelos 1 e 2, e ao nível de $5 \%$ no Modelo 3. Esse resultado é consistente com estudos anteriores (HEALY, PALEPU; RUBACK, 1992; SWITZER, 1996; DICKERSON, GIBSON; TSAKALOTOS, 1997; POWELL; STARK, 2005), porém o nível de persistência no desempenho das companhias, entre $8 \%$ e $12 \%$, foi inferior ao reportado em outros estudos, a exemplo das pesquisas de Dickerson, Gibson e Tsakalotos (1997) e de Power e Stark (2005), em que as firmas observadas apresentaram uma taxa persistência no desempenho superior a $50 \%$.

Assumindo outra perspectiva, as evidências demonstram que houve um aumento no desempenho das empresas após as fusões e aquisições, demonstrando que essas operações são estratégias viáveis para obtenção de lucros, desempenho superior, sinergias operacionais, ganhos de escala e expansão das firmas (RAO-NICHOLSON; SALABER; CAO, 2016; HANIFI; VAHEDI, 2016; LI; LI; WANG, 2016). Contudo, esse resultado mostrou-se abaixo do reportado por outros estudos que evidenciaram um aumento no desempenho das companhias após F\&As superior a $50 \%$ (SWITZER, 1996; DICKERSON; GIBSON; TSAKA- 
LOTOS, 1997; POWELL; STARK, 2005; HANIFI; VAHEDI, 2016).

Com relação ao tipo de crescimento, observou-se que o crescimento por fusão e aquisição (CFA) apresentou-se estatisticamente significante ao nível de $5 \%$ nos Modelos 1 e 3. Contudo, observou-se uma relação negativa entre essa variável e o desempenho das companhias após as operações de fusões e aquisições. Por outro lado, o crescimento interno (CI) mostrou-se positivamente relacionado com o desempenho das companhias, sendo estatisticamente significante ao nível de $1 \%$ e $5 \%$ nos Modelos 1 e 2, respectivamente. Esses resultados sugerem que, mesmo após as combinações de negócios, o retorno proporcionado pelo crescimento interno das companhias foi superior ao oriundo das F\&As, corroborando com os achados de Dickerson, Gibson e Tsakalotos (1997).

Entretanto, segundo a literatura, por ser a fusão e aquisição a estratégia mais utilizada pelos administradores para fazer crescer as empresas, expandindo suas atividades por meio de operações transnacionais, nem sempre tais combinações de negócios visam o aumento da lucratividade, mas em muitos casos são utilizadas apenas com o objetivo de maximizar a utilidade gerencial dos administradores em detrimento da maximização dos lucros da firma (HANIFI; VAHEDI, 2016; LI; LI; WANG, 2016; ZHONG, 2016; YAGHOUBI et al., 2016).

De acordo com os resultados apresentados na Tabela 2, outra variável que apresentou uma relação positiva com o desempenho das companhias após as operações de fusões e aquisições foi o tamanho das companhias (Tam), apresentando-se estatisticamente significante ao nível de $5 \%$ no modelo 1 . Segundo Switzer (1996) e Rao-Nicholson, Salaber e Cao (2016), o aumento no tamanho das firmas após uma combinação de negócios pode ser decorrente da realização de sinergias e/ou do aumento no poder de mercado após as fusões e aquisições, entretanto, o baixo valor do coeficiente dessa variável sugere que as F\&As produziram baixos ganhos para as companhias envolvidas (SWITZER, 1996; RAO-NICHOLSON; SALABER; CAO, 2016).

Observa-se ainda que o aumento no tamanho das empresas é considerada uma das estratégias ou motivos utilizados pelos gestores para obterem ganhos de escalas, sinergias operacionais, maior participação de mercado, monopólio e utilidade gerencial, buscando com isso enfrentar os desafios e a concorrência em mercados cada vez mais integrados (CAMARGOS; BARBOSA, 2010; ZHONG, 2016; RAO-NICHOLSON; SALABER; CAO, 2016).

Com relação às demais variáveis explicativas, os resultados demonstram que o endividamento (Endiv) afetou negativamente no desempenho das companhias após as operações de fusões e aquisições, sendo estatisticamente significante ao nível de $1 \%$ e $5 \%$ nos modelos 1 e 2 , respectivamente. Esse resultado corroborou com o preconizado na literatura, mostrando ser o nível de endividamento um dos determinantes da lucratividade e do desempenho organizacional (NEUMAN; BÖBEL; HAID, 1983; DICKERSON; GIBSON; TSAKALOTOS, 1997).

Além disso, observou-se que, em relação ao tipo de recurso utilizado para financiar as operações de fusões e aquisições, a variável dummy Misto apresentou significância estatística ao nível de 5\% no Modelo 1. Esse resultado sugere que a utilização de mais um tipo de recurso pelas empresas para financiar suas operações de fusões e aquisições impactaram negativamente no seu desempenho econômico-financeiro, não corroborando com as evidências reportadas por Gosh (2001) e Rao-Nicholson, Salaber e Cao (2016).

Além disso, observa-se que esta evidência pode sugerir que a estratégia de financiamento utilizado pela empresa para financiar suas operações de F\&As pode ser um dos motivos que as levam a apresentar uma redução na lucratividade após a efetivação da combinação de negócios (HEALY; PALEPU; RUBACK, 1992; GOSH, 2001; RAO-NICHOLSON; SALABER; CAO, 2016).

De acordo com Gosh (2001), em geral, operações financiadas por mais de uma fonte de recurso levam as companhias a incorrerem em novas despesas para efetivação da fusão e aquisição, causando posteriormente uma redução no desempenho organizacional após a combinação de negócios. Ademais, o efeito negativo provocado pela variável Misto pode ter sido causado devido à proporção de recurso utilizado pela companhia para financiar essas operações (GOSH, 2001; RAO-NICHOLSON; SALABER; CAO, 2016).

Por fim, considerando os resultados expostos, observou-se que o desempenho econômico-financeiro das companhias que realizaram operações de F\&As foi persistente ao longo do período analisado, mostrando 
que, após as combinações de negócios, as empresas apresentaram uma melhora em seu desempenho devido à implementação dessa estratégia. Contudo, verificou-se que o aumento e a persistência no desempenho das firmas podem ser considerados pouco expressivos, quando comparados aos reportados por outras pesquisas.

\section{Conclusões}

O presente trabalho teve como objetivo identificar os efeitos provocados pelas fusões e aquisições no desempenho econômico-financeiro das empresas brasileiras de capital aberto envolvidas nessas combinações de negócios. Para isso, aplicou-se o Método dos Momentos Generalizados-Sistema para testar a relação entre o desempenho financeiro das companhias após as combinações de negócios com o tipo de crescimento (interno das companhias e por fusão e aquisição), tipo de financiamento utilizado, entre outras variáveis.

A partir da análise das estimações de três modelos, verificou-se que houve um aumento no desempenho das companhias entre $8 \%$ e $12 \%$ durante o período investigado. Noutra perspectiva, os resultado sugerem que o desempenho financeiro das companhias foi persistente ao longo do período analisado, sendo as F\&As uma estratégia lucrativa.

Com relação ao tipo de crescimento, observou-se que o crescimento interno das companhias proporcionou um maior retorno se comparado ao crescimento decorrente das operações de fusões e aquisições, podendo ser considerado um fator primordial para o desempenho das companhias investigadas.

Os resultados demonstraram que em operações financiadas por mais de um tipo de recurso provocou um efeito negativo no desempenho das empresas durante o período analisado, revelando que a utilização dessas fontes de recursos pelas empresas, para financiar suas operações de F\&A, provocaram uma redução no seu desempenho, possivelmente provocada pelo aumento de despesas decorrentes da utilização desses recursos, conforme sugere a literatura.

As evidências também demonstraram que operações realizadas entre empresas do mesmo setor econômico e o aumento no tamanho geraram ganhos para as companhias, conforme preceitua a Hipótese das Sinergias. Foi possível confirmar, ainda, que o nível de endividamento das companhias afetou negativamente o desempenho das empresas após a efetivação das fusões e aquisições, mostrando-se ser um dos determinantes do desempenho corporativo, conforme relatado pela literatura.

Por fim, considerando as evidências, pode-se dizer que as F\&As produziram ganhos no desempenho econômico-financeiro das companhias, geraram sinergias pelo aumento no tamanho das firmas, evidenciando aumento de poder de mercado e que o crescimento internou produziu um maior retorno se comparado ao crescimento por fusão e aquisição. Por outro lado, as operações financiadas por mais de uma modalidade de recursos reduziram o desempenho financeiro das companhias durante o período investigado. Ademais, ressalta-se que as conclusões apresentadas devem ser consideradas com cautela e não permitem que sejam realizadas inferências que extrapolem a amostra de empresas e de operações de fusões e aquisições investigadas nesta pesquisa.

\section{REFERÊNCIAS}

AHMMMAD, M. F. et al. Knowledge transfer and crossborder acquisition performance: the impacto f cultural distance and employee retention. International

Business Review, [S.l.], v. 25, n. 1, p. 66-75, 2016.

ARRELANO, M.; BOND, S. Some tests of specification for panel data: Monte Carlo evidence and an application to employment equations. The Review of Economics Studies, [S.l.], v. 58, n. 2, p. 277-297, 1991.

ARRELANO, M.; BOVER, O. Another look at the instrumental variable estimation of error-components models. Journal of Econometrics, [S.l.], v. 68, n. 1, p. 29-51, 1995.

ASSOCIAÇÃO BRASILEIRA DAS ENTIDADES DOS MERCADOS FINANCEIROS E DE CAPITAIS (ANBIMA). (2013). Fusões e Aquisições. Boletim ANBIMA, [S.l.], VII, Primeiro Semestre de 2012. Disponível em: <http:// www.portal.anbima.com.br>. Acesso em: 15 jan. 2013.

BERKOVITCH, E.; NARAYANAM, M. P. Motives for takeovers: an empirical investigation. The Journal of Financial and Quantitative Analysis, [S.I.], v. 28, n. 3, p. 347-362, 1993. 
BHABRA, H. S.; HUANG, J. An empirical investigation of mergers and acquisitions by Chinese listed companies, 1997-2007. Journal of Multinational Financial Management, [S.l.], v. 23, n. 3, p.186-207, 2013.

BLUNDELL, R.; BOND, S. Initial conditions and restricitions in dynamic panel data models. Journal of Econometrics, [S.l.], v. 87, n. 1, p.115-143, 1998.

BRADLEY, M.; DESSAI, A.; KIM, E. H. Synergistic gains from corporate acquisitions and their division between the stockholders of target and acquiring firms. Journal of Financial Economics, [S.1.], v. 21, n. 1, p. 3-40, 1988.

BROOKS, C. Introductory econometrics for finance. 2. ed. Cambridge: Cambridge University Press, 2008.

CAMARGOS, M. A.; BARBOSA, F. V. Fusões, aquisições e takeovers: um levantamento teórico dos motivos, hipóteses testáveis e evidências empíricas. Caderno de Pesquisas em Administração, [S.I.], v. 10, n. 2, p.1738, 2003.

CAMARGOS, M. A.; BARBOSA, F. V. Análise do desempenho econômico-financeiro e da criação de sinergias em processo de fusões e aquisições do mercado brasileiro, ocorridos entre 1995 e 1999. Caderno de Pesquisa em Administração, [S.1.], v. 12, n. 2, p. 99115, 2005.

CAMARGOS, M. A.; BARBOSA, F. V. Fusões e aquisições de empresas brasileiras: criação de valor e sinergias operacionais. Revista de Administração de Empresas, [S.l.], v. 49, n. 2, p- 206-220, 2009.

CAMARGOS, M. A.; BARBOSA, F. V. Fusões e aquisições de empresas brasileiras: sinergias operacionais, gerenciais e rentabilidade. Revista Contabilidade Vista \&

Revista, [S.1.], v. 21, n. 1, p. 69-99, 2010.

CAMARGOS, M. A.; COUTINHO, E. S. A teoria da firma e a fundamentação teórica para fusões e aquisições: uma análise de suas interfaces. RAC-Eletrônica, [S.l.], v. 2, n. 2, p. 273-295, 2005.

COLARES, A. C. V.; BORGES, D. L. Investimentos em fusões e aquisições (F\&A): um estudo sobre as relações com o desempenho financeiro. In: CONGRESSO NACIONAL DE ADMINISTRAÇÃO E CIÊNCIAS
CONTÁBEIS, 2., 2011, Rio de Janeiro. Anais... Rio de Janeiro: AdCont, 2011.

COOPELAND, T. E.; WESTON, J. F; SHASTRI, K. Financial theory and corporate policy. 4. ed. New York: Pearson Education, 2005.

DAMADORAN, A. The value of synergy. New York University - Stern School of Busniess. Working Paper, [S.l.], p. 1-47, 2005. Disponível em: <http://www.papers. ssrn.com >. Acesso em: 20 jul. 2013.

DICKERSON, A. P.; GIBSON, H. D.; TSAKALOTOS, E. The impact of acquisitions on company performance: evidence from a large panel of UK firms. Oxford Economics Papers, [S.l.], v. 49, n. 3, p. 344-361, 1997.

FIRTH, M. Shareholder returns, and theory of the firm.

The Quarterly Journal of Economics, [S.I.], v. 94, n. 2, p. 235-260, 1980.

GOSH, A. Does operating performance really improve following corporate acquisitions? Journal of Corporate Finance, [S.l.], v. 7, n. 2, p. 151-178, 2001.

GUGLER, K.; MUELLER, D. C; WEICHSELBAUMER, $M$. The determinants of mergers waves: an international perspective. International Journal of Industrial Organization, [S.l.], v. 30, n. 1, p. 1-15, 2012.

GUGLER, K.; MUELLER, D. C; YOUTOGLU, B. B; ZULEHNER, C. The effects of mergers: an international comparison. International Journal of Industrial Organization, [S.I.], v. 21, n. 5, p. 625-653, 2003.

HANIFI, F; VAHEDI, S. The effect of acquisitions on firm performance: evidenc Tehran Stock Exchange. Accouting, [S.l.], v. 2, n. 3, p. 93-102, 2016.

HEALY, P. M.; PALEPU, K. G.; RUBACK, R. S. Does corporate performance improve after mergers? Journal of Financial Economics, [S.l.], v. 31, n. 2, p. 135-175, 1992.

IKEDA, K.; DOI, N. The performances of merging firms in japonese manufacturing industry: 1964-1975. The Journal of Industrial Economics, [S.I.], v. 31, n. 3, p. 257-266, 1983. 
JENSEN, M. C.; MECKLING, W. H. Theory of the firm: managerial behavior, agency costs and ownership structure. Journal of Financial Economics, [S.I.], v. 31, n. $4,305-360$.

JENSEN, M. C.; RUBACK, R. S. The market for corporate control: the scientific evidence. Journal of Financial Economics, [S.l.], v. 11, n. 1-4, p. 5-50, 1983.

KPMG. Pesquisa de fusões e aquisições 2013 - $\mathbf{1}^{\circ}$ trimestre. [2013]. Disponível em: <http://www.kpmg. com/BR> . Acesso em: 20 jun. 2013.

LAU, B.; PROIMOS, A.; WRIGHT, S. Accounting measures of operating performance outcomes for Australian mergers. Journal of Applied Accounting Research, [S.I.], v. 9, n. 3, p. 168-180, 2008.

LI, J.; LI, P.; WANG, B. Do cross-border acquisitions create value? Evidence from overseas acquisitions by chinese firms. International Business Review, [S.I.], v. 25, n. 2, p. 471-483, 2016.

MANNE, H. G. Mergers and the market for corporate control. The Journal of Political Economy, [S.l.], v. 73, n. 2 , p. $110-120,1965$.

MARRIS, R. A model of "managerial" enterprise. The Quarterly Journal of Economics, [S.1.], v. 77, n. 2, p. 185-209, 1963.

MARTINS, G. A; THEÓPHILO, C. R. Metodologia da investigação cientifica para Ciências Sociais Aplicadas. 2. ed. São Paulo: Atlas, 2009.

MATIAS, A. B.; PASIN, E. M. A geração de sinergias e seus impactos na rentabilidade das empresas nos casos de fusões e aquisições. Revista de Administração, [S.l.], v. 36, n. 1, p. 5-13, 2001.

MEEKS, G. Disappointing marriage: a study of the gains from merger. Cambridge: Cambridge University Press, 1977.

MITCHELL, M. L.; MULHERIN, J. H. The impact of industry schoks on takeover and restructuring activity. Journal of Financial Economics, [S.1.], v. 41, n. 2, p. 193-229, 1996.

MUELLER, D. C. A theory of conglomerate mergers. The Quarterly Journal of Economics, [S.l.], v. 83, n. 4, p. 643-659, 1969.
NELSON, R. L. Merger movements in american industry, 1895-1956. Princeton: Princeton University Press, 1959. Disponível em: <http://www.nber.org > . Acesso em: 20 jun. 2013.

NEUMAN, M.; BÖBEL, I.; HAID, A. Bussiness cycle and industrial market power: an empirical investigation for West German industries, 1905-1077. The Journal of Industrial Economics, [S.l.], v. 32, n. 2, p. 187-196, 1983.

NG, Y. K. Utility and profit maximization by an ownermanager: towards a general analysis. The Journal of Industrial Economics, [S.I.], v. 23, n. 2, p. 97-108, 1974.

NIESTEN, E.; JOLINK, A. The impact of alliance management capabilities on alliance attributes and performance: a literature review. International Journal of Management Reviews, [S.l.], v. 17, n. 1, p. 69-100, 2015.

POWELL, R. G; STARK, A. W. Does operating performance increase post-takeover for UK takeovers? A comparison of performance measures and benchmarks. Journal of Corporate Finance, [S.l.], v. 11, n. 1, p. 293 $317,2005$.

RANI, N; YADAV, S. S; JAIN, P. K. Post-M\&A operating performance of Indian acquiring firms: a Du Pont analysis. International Journal of Economics and Finance, [S.l.], v. 5, n. 8, p. 65-73, 2013.

RAO-NICHOLSON, R.; SALABER, J.; CAO, T. H. Longterm performance of mergers and acquisitions in ASEAN. Research in International Business and Finance, [S.l.], v. 36, p. 373-387, 2016.

ROCHA, F.; IOOTTY, M.; FERRAZ, J. C. Desempenho das fusões e aquisições na indústria brasileira da década de 90: a ótica das empresas adquiridas. Revista de Economia Contemporânea, [S.l.], v. 5, p. 69-102, 2001.

ROODMAN, D. How to do xtabond2: an introduction to difference and system GMM in Stata. The Stata Journal, [S.l.], v. 9, n. 1, p. 86-136, 2009.

SETH, A; SONG, K. P; PETTIT, R. Synergy, managerialism or hubris? An empirical examination of motives for foreign acquisitions of US firms. Journal of International Business Studies, [S.I.], v. 31, n. 3, p. 387-405, 2000. 
SWITZER, J. A. Evidence on real gains in corporate acquisitions. Journal of Economics and Business, [S.l.], v. 48, n. 5, p. 443-460, 1996.

TRICHES, D. Fusões, aquisições e outras formas de associação entre empresas no Brasil. Revista de Administração, [S.l.], v. 31, n. 1, p. 14-31, 1996.

WOOD JR., T; VASCONCELOS, F. C; CALDAS, M. P. Fusões e aquisições no Brasil. RAE - Executivo, [S.l.], v. 2, n. 4, p. 41-45, 2004.

WOOLDRIDGE, J. M. Econometric analysis of cross section and panel data. London: MIT Press, 2002.

YAGHOUBI, R.; YAGHOUBI, M.; LOCKE, S.; GIBB, J. Mergers and acquisitions: a review. Part 1 . Studies in Economics and Finance, [S.I.], v. 33, n. 1, p. 147-188, 2016.

ZHONG, Z. Empirical analysis in the political connection and the performance of merger and acquisition. Journal of Service and Management, [S.I.], v. 9, n. 1, p. 1-9, 2016. 